\title{
Efficacy of single bevacizumab injection as adjuvant therapy to laser photocoagulation in macular edema secondary to branch retinal vein occlusion
}

This article was published in the following Dove Press journal:

Clinical Ophthalmology

31 October 2016

Number of times this article has been viewed

\section{Arief S Kartasasmita \\ Siska Takarai \\ Astriviani Switania \\ Sutarya Enus}

Department of Ophthalmology, Universitas Padjadjaran/Cicendo National Eye Hospital, Bandung, Indonesia
Correspondence: Arief S Kartasasmita Department of Ophthalmology, Universitas Padjadjaran, Jl Cicendo No 4, Bandung 40I4I, Indonesia

Email a.kartasasmita@unpad.ac.id
Background: Macular grid laser photocoagulation remains the standard treatment for macular edema secondary to branch retinal vein occlusion (BRVO). One possible strategy for treating macular edema is to inhibit VEGF activity by competitive binding of VEGF with an anti-VEGF antibody, suggesting the therapy option with bevacizumab. However, multiple injections of anti-VEGF may lead to complications and high cost.

Purpose: The aim of this study was to evaluate the improvement in visual acuity and central macular thickness after combination therapy of laser photocoagulation with single intravitreal bevacizumab injection in macular edema secondary to BRVO.

Methods: Nineteen patients with macular edema secondary to BRVO were assigned to either the group of nine patients in combination therapy of laser photocoagulation with intravitreal bevacizumab or the group of ten patients in the laser photocoagulation therapy. Complete ophthalmologic examinations were performed just before the therapy and at 1 month following the therapy. Changes in visual acuity were tested with the logarithm of minimum angle of resolution (logMAR), and central macular thickness was measured by optical coherence tomography (OCT).

Results: Combination therapy of laser photocoagulation and single intravitreal bevacizumab injection resulted in a significantly better visual acuity compared to laser photocoagulation therapy $(0.35$ versus $0.13 \log$ MAR; $P=0.041)$ and reduced macular thickness by $120.33 \mu \mathrm{m}$ versus $71.50 \mu \mathrm{m}(P=0.277)$, although this difference was not significant.

Conclusion: Laser photocoagulation combined with a single intravitreal bevacizumab has a substantial effect on increasing visual acuity in macular edema secondary to BRVO.

Keywords: bevacizumab, branch retinal vein occlusion, grid laser photocoagulation, macular edema, vascular endothelial growth factor

\section{Introduction}

Branch retinal vein occlusion (BRVO) is one form of retinal vascular disease and is the second leading cause of loss of vision after diabetic retinopathy. ${ }^{1}$ According to Klein Population Study (Beaver Dam Study), the incidence of BRVO was approximately $1.8 \%$ and the prevalence of BRVO was $0.3 \%-1.1 \%{ }^{2,3}$ According to Blue Mountain Eye Study, the incidence of BRVO was 1.6\%. ${ }^{3,4}$ The most common symptom among BRVO patients is decreased visual acuity and sudden loss of vision due to macular edema. ${ }^{1,2}$

Since the Branch Vein Occlusion Study has been published, grid laser photocoagulation has been the standard treatment for macular edema in BRVO patients. The Branch Vein Occlusion Study reported that the mean increase in visual 
acuity was 1.33 lines in BRVO patients treated with grid laser photocoagulation. ${ }^{5,6}$ Limited visual outcome from grid laser photocoagulation therapy raised questions of alternative therapy to improve visual outcome in macular edema secondary to BRVO. ${ }^{6}$

Recent studies showed that there was an increased level of intraocular VEGF in patients with retinal vein occlusion. ${ }^{6,7}$ VEGF has been noted as an important factor correlated with increased retinal vascular permeability and macular edema in retinal vein occlusion. ${ }^{8,9}$ Administration of the anti-VEGF agent bevacizumab is expected to reduce macular edema and reinstitute visual outcome. ${ }^{9,10}$

Studies to investigate the use of anti-VEGF in retinal vein occlusion are rapidly growing. The BRAVO and CRUISE studies showed good results in maintaining central retinal thickness and visual outcomes. ${ }^{6,11}$ However, all of the studies were done using multiple injections of anti-VEGF, with the least mean of injections being two. ${ }^{9-11}$ Repeated and long-term injections may increase the chance of ocular and systemic complications. ${ }^{12}$ Multiple injections also add to the total cost of treatment. ${ }^{13}$

Therefore, this study aimed at finding out whether a single injection of bevacizumab could improve the clinical outcome of macular edema secondary to BRVO.

\section{Subjects and methods}

This was a clinical trial study of 19 patients diagnosed with macular edema secondary to BRVO. Subjects were recruited after ethical clearance was obtained from The Ethical Committee of Padjadjaran University. Subjects were recruited consecutively. Inclusion criteria were patients (less than 3 months of onset) with diagnosis of macular edema secondary to BRVO, age $>20$ years, intraocular pressure less than $21 \mathrm{mmHg}$, adequate pupillary dilation, clear ocular media adequate for optical coherence tomography (OCT) examination, and central macular thickness greater than $250 \mu \mathrm{m}$. Exclusion criteria were history of other retinal diseases that could cause macular edema, history of intraocular surgery, retinal laser therapy, intravitreal triamcinolone injection or anti-VEGF injection, and macular ischemia. After signing the written informed consent, 19 subjects were chosen and divided into two groups based on block randomization. Group A ( $n=9)$ was treated with laser photocoagulation therapy in combination with intravitreal bevacizumab injection, while Group B ( $n=10)$ was treated with laser photocoagulation therapy alone.

For the laser therapy alone group, the laser surgery was performed when the hemorrhage had already been absorbed, maximum 3 months after the onset, with an average of 5 weeks.
Macular laser photocoagulation therapy was performed using contact lens and double coupling frequency $\mathrm{Nd}$ :Yag (neodymium-doped yttrium aluminium garnet) laser. Grid laser photocoagulation was performed at 500-3,000 $\mu \mathrm{m}$ from central fovea with $50-100 \mu \mathrm{m}$ spot size, time of exposure 0.05-0.1 seconds, moderate burn intensity, and the distance between spots is 1-2 spots. Subjects treated with laser photocoagulation therapy were reexamined 1 week, 1 month, and 3 months posttreatment. During 1-month and 3-month follow-up, OCT was performed to measure macular thickness.

The intravitreal bevacizumab injection of $1.25 \mathrm{mg}$ or $0.05 \mathrm{~mL}$ was given to those subjects in the combination of therapy group in an operating room. At 1 month follow-up after the injection, subjects were treated with laser photocoagulation therapy. Laser photocoagulation method was equal to the other group; follow-ups were conducted after 1 week, 1 month, and 3 months of laser therapy to measure macular thickness via OCT.

The main outcome measures were visual acuity, macular thickness, and the difference of macular thickness in both groups.

Statistical analysis was performed by conducting Student's $t$-test and Mann-Whitney test on SPSS 15.0 (SPSS Inc., Chicago, IL, USA) to determine the difference in visual acuity and macular thickness on pretreatment and posttreatment on the two groups.

\section{Results}

Table 1 shows that there is no significant difference in age between the two groups $(P=0.72)$. There was no significant difference between the two groups with regard to sex $(P=1.00)$. Characteristics of systemic conditions do not show

Table I Characteristics of subjects

\begin{tabular}{|c|c|c|c|}
\hline \multirow[t]{2}{*}{ Characteristics } & \multicolumn{2}{|l|}{ Group } & \multirow[t]{2}{*}{$P$-value } \\
\hline & $\begin{array}{l}\text { Group A } \\
(n=9)\end{array}$ & $\begin{array}{l}\text { Group B } \\
(n=10)\end{array}$ & \\
\hline Age (years) & & & 0.72 \\
\hline Mean (SD) & $57.8(14.4)$ & $55.5(13)$ & \\
\hline Range & $42-78$ & $27-68$ & \\
\hline Sex & & & 1.0 \\
\hline Male & 2 & 3 & \\
\hline Female & 7 & 7 & \\
\hline Systemic conditions & & & 0.53 \\
\hline Hypertension & 6 & 8 & \\
\hline Diabetes & 2 & 0 & \\
\hline Hypertension + diabetes & 1 & I & \\
\hline None & 0 & $\mathrm{I}$ & \\
\hline
\end{tabular}

Notes: Group A = grid laser photocoagulation + intravitreal bevacizumab; Group B = grid laser photocoagulation.

Abbreviation: SD, standard deviation. 
Table 2 Comparison of visual acuity on Group A and Group B at I-month follow-up

\begin{tabular}{|c|c|c|c|}
\hline \multirow[t]{2}{*}{ Visual acuity } & \multicolumn{2}{|l|}{ Group } & \multirow[t]{2}{*}{$P$-value } \\
\hline & Group A $(n=9)$ & Group B $(n=10)$ & \\
\hline \multicolumn{4}{|l|}{ Pretreatment } \\
\hline Mean (SD) & $1.17(0.34)$ & $0.75(0.25)$ & \\
\hline Range & $0.60-1.64$ & $0.36-1.02$ & \\
\hline \multicolumn{4}{|l|}{ Posttreatment } \\
\hline Mean (SD) & $0.81(0.23)$ & $0.62(0.19)$ & \\
\hline Range & $0.46-1.04$ & $0.40-0.96$ & \\
\hline \multicolumn{4}{|c|}{ Difference between pretreatment and posttreatment } \\
\hline Mean (SD) & $0.35(0.25)$ & $0.13(0.20)$ & 0.041 \\
\hline Range & $0.04-0.80$ & $-0.12-0.50$ & \\
\hline
\end{tabular}

Notes: Group $A$ = grid laser photocoagulation + intravitreal bevacizumab, Group $B=$ grid laser photocoagulation.

Abbreviation: SD, standard deviation.

a significant difference between the two groups $(P=0.53)$. These results show that the sample of this study was homogenous based on age, sex, and systemic conditions of both groups.

The result of visual acuity examination for baseline was conducted using Mann-Whitney test since the data was not normally distributed. However, independent $t$-test was performed to examine the visual acuity after surgery and laser treatment because the data was normally distributed. The outcomes are shown in Tables 2 and 3, with the result of $t$-test shown with confidence interval $95 \%$. A significant difference in visual acuity between the two groups at 1-month and 3-month follow-up ( $P=0.041$ and $P=0.037$, respectively) can be observed.

Macular thickness was measured using OCT on the day of admission and 1 month after treatment. As can be seen from the values given in Tables 4 and 5, no significant difference in macular thickness between the two groups was observed $(P=0.277$ and $P=0.783)$.

Table 3 Comparison of visual acuity on Group A and Group B at 3-month follow-up

\begin{tabular}{|c|c|c|c|}
\hline \multirow[t]{2}{*}{ Visual acuity } & \multicolumn{2}{|l|}{ Group } & \multirow[t]{2}{*}{$P$-value } \\
\hline & Group A $(n=9)$ & Group B $(n=10)$ & \\
\hline \multicolumn{4}{|l|}{ Pretreatment } \\
\hline Mean (SD) & $1.17(0.34)$ & $0.75(0.25)$ & \\
\hline Range & $0.60-1.64$ & $0.36-1.02$ & \\
\hline \multicolumn{4}{|l|}{ Posttreatment } \\
\hline Mean (SD) & $0.71(0.27)$ & $0.62(0.13)$ & \\
\hline Range & $0.42-1.02$ & $0.32-0.96$ & \\
\hline \multicolumn{4}{|c|}{ Difference between pretreatment and posttreatment } \\
\hline Mean (SD) & $0.35(0.25)$ & $0.13(0.20)$ & 0.037 \\
\hline Range & $0.02-0.72$ & $-0.10-0.52$ & \\
\hline
\end{tabular}

Notes: Group $A=$ grid laser photocoagulation + intravitreal bevacizumab Group B = grid laser photocoagulation.

Abbreviation: SD, standard deviation.
Table 4 Comparison of macular thickness on Group $A$ and Group B at I-month follow-up

\begin{tabular}{|c|c|c|c|}
\hline \multirow[t]{2}{*}{ Macular thickness } & \multicolumn{2}{|l|}{ Group } & \multirow[t]{2}{*}{$P$-value } \\
\hline & Group A $(n=9)$ & Group B $(n=10)$ & \\
\hline \multicolumn{4}{|l|}{ Pretreatment } \\
\hline Mean (SD) & $497(106.42)$ & $405.40(106.15)$ & \\
\hline Range & $3|8-65|$ & $257-523$ & \\
\hline \multicolumn{4}{|l|}{ Posttreatment } \\
\hline Mean (SD) & $376.67(99.05)$ & $333.90(71.02)$ & \\
\hline Range & $257-519$ & $240-435$ & \\
\hline \multicolumn{4}{|c|}{ Difference between pretreatment and posttreatment } \\
\hline Mean (SD) & $120.33(100.93)$ & $71.50(88.57)$ & 0.277 \\
\hline Range & $16-317$ & $-35-204$ & \\
\hline
\end{tabular}

Notes: Group $A$ = grid laser photocoagulation + intravitreal bevacizumab, Group B = grid laser photocoagulation.

Abbreviation: SD, standard deviation.

\section{Discussion}

The most common symptom in patients with BRVO is a sudden loss of vision due to edema. ${ }^{2}$ There are two pathogenic mechanisms in macular edema secondary to BRVO: Starling force and increased VEGF level. ${ }^{7,8}$ In BRVO, there is an increase in intravascular pressure and plasma transudation into the extracellular space resulting in macular edema (Starling force). ${ }^{8}$ BRVO also causes hypoxia in the retina. Therefore, the level of VEGF, a vascular permeability factor, increases due to hypoxia, and this change will be excreted in the retina, leading to increase in retinal vascular permeability that worsens the macular edema that has already occurred as a result of the Starling force. ${ }^{8,14}$ This occurs because the arteriovenous structure in the retina is a closed system with few collateral vessels. If the obstruction occurs in the vein, it results in retinal ischemia. ${ }^{15}$

The anti-VEGF antibody, bevacizumab, is a monoclonal antibody that binds to all VEGF-A isoform. Bevacizumab

Table 5 Comparison of macular thickness on Group A and Group B at 3-month follow-up

\begin{tabular}{llll}
\hline Macular thickness & Group & P-value \\
\cline { 2 - 3 } & Group A (n=9) & Group B (n=10) & \\
\hline Pretreatment & $497(106.42)$ & $405.40(106.15)$ & \\
Mean (SD) & $318-651$ & $257-523$ & \\
$\quad$ Range & & & \\
Posttreatment & $326.44(89.9057)$ & $320.2(66.545)$ & \\
Mean (SD) & $221-454$ & $240-422$ & \\
Range & I70.56 (I03.663) & $97.4(77.07)$ & 0.783 \\
Difference between pretreatment and posttreatment \\
Mean (SD) & $-353-53$ & $-198-47$ & \\
Range &
\end{tabular}

Notes: Group $A=$ grid laser photocoagulation + intravitreal bevacizumab, Group $B=$ grid laser photocoagulation.

Abbreviation: SD, standard deviation. 
inhibits VEGF binding to its receptor such that capillary permeability is maintained and macular edema is reduced. ${ }^{9}$

The US Food and Drug Administration has approved intravenous bevacizumab injection for colorectal cancer treatment. The use of intravitreal bevacizumab injection is still off the label. However, intravitreal bevacizumab has been widely used and has been proven to be effective in inhibiting neovascularization in many retinal proliferative vascular diseases such as choroid neovascularization, proliferative diabetic retinopathy, neovascular glaucoma, and diabetic macular edema. ${ }^{16-19}$ Studies reported that intravitreal bevacizumab injection is not inferior compared to intravitreal ranibizumab injection, an intravitreal antiVEGF that has been approved by the US Food and Drug Administration for the treatment of age-related macular degeneration. ${ }^{20,21}$ Bevacizumab is also more cost-effective than ranibizumab. ${ }^{22}$

A study by Solaiman et $\mathrm{al}^{17}$ on patients with diabetic macular edema given a combination treatment of macular laser therapy and anti-VEGF bevacizumab compared to laser therapy alone showed a significant increase of visual acuity at the 1-month follow-up in the combination treatment group. At 1-month follow-up, the mean decreases of macular thickness were $49.88 \mu \mathrm{m}$ in the laser group and $110.30 \mu \mathrm{m}(P<0.05)$ in the combination treatment group. Study on pro re nata bevacizumab to grid laser on BRVO showed significant resolution of macular edema. ${ }^{16}$ That study was also similar to other studies that demonstrate the effectiveness of anti-VEGF in retinal vein occlusion (RVO) (shown in Table 6). ${ }^{16,23-27}$ Another study showed that intravitreal bevacizumab injection resulted a better outcome in patients with diabetic macular edema compared to treatment with laser photocoagulation, such as in DRCR and BOLT study. ${ }^{18,28}$ Laser photocoagulation is directed to the retinal pigment epithelium so that the oxygen can diffuse directly to

Table 6 Published studies of anti-VEGF on RVO

\begin{tabular}{|c|c|c|c|}
\hline & $\begin{array}{l}\text { Mean } \\
\text { injection (n) }\end{array}$ & $\begin{array}{l}\text { Follow-up } \\
\text { duration } \\
\text { (months) }\end{array}$ & $\begin{array}{l}\text { Mean difference } \\
\text { on CRT in 6th } \\
\text { month }(\mu \mathrm{m})\end{array}$ \\
\hline Risard et $\mathrm{al}^{23}$ & 6.9 & 24 & -266 \\
\hline Campochiaro et $\mathrm{al}^{24}$ & 2 & 24 & -264.4 \\
\hline Spaide et $\mathrm{al}^{25}$ & 6 & 12 & -294 \\
\hline Campochiaro et $\mathrm{al}^{26}$ & NA & 6 & -212 \\
\hline Alfaro et $\mathrm{al}^{30}$ & 7 & 12 & -164 \\
\hline Pieramici et $\mathrm{al}^{27}$ & 4.5 & 24 & -88 \\
\hline Wykrota et $\mathrm{al}^{3 \mathrm{l}}$ & 3.2 & 6 & -366 \\
\hline Narayanan et al ${ }^{16}$ & 3.3 & 12 & -201.7 \\
\hline
\end{tabular}

Abbreviations: RVO, retinal vein occlusion; CRT, central retinal thickness; NA, not applicable. the internal retinal layer through the laser scar. When tissue hypoxia is relieved, the arterial resistance will increase and vein hydrostatic pressure will decrease such that plasma transudation will lessen and macular edema will resolve. ${ }^{29}$

Based on the hypothesis that macular edema secondary to BRVO causes decreased visual acuity, many efforts have been made to reduce macular edema to achieve improvement in visual acuity after BRVO. However, resolution of macular edema is followed by loss of photoreceptors that causes limited improvement of visual acuity. These findings explain the limited visual acuity improvement in patients with macular edema secondary to BRVO after laser photocoagulation treatment alone. Therefore, intravitreal bevacizumab injection as an adjuvant therapy in the early course of BRVO is intended to maintain the physiologic integrity of both the internal and the external photoreceptor structure. Therefore, the laser photocoagulation treatment will not cause massive loss of photoreceptors. This combination treatment then leads to decreased macular edema and maximal improvement of visual acuity.

Grid laser photocoagulation was useful to reduce macular edema or intraretinal fluid collection. Laser photocoagulation can also cause photoreceptor cell damage and degeneration. Anti-VEGF treatment in the early course of acute BRVO can reduce VEGF level to maintain vascular permeability, and as a result will reduce serous retinal detachment as a complication for macular edema.

Laser photocoagulation therapy is considered unsafe if it is performed in the acute phase of BRVO. It needs approximately a 3-month delay to facilitate the hemorrhage absorbed. However, it should be performed within the first 3 months, because after that period, the macular edema may worsen and cause retinal cell damage and permanent loss of vision. For that reason, in this study, bevacizumab was given at the beginning of the study, and the grid laser was done after most of the retinal hemorrhage was absorbed, but not later than 3 months. With this approach, maximal improvement of vision and decrease of macular thickness could be achieved. The role of intravitreal bevacizumab in this study was intended to facilitate rapid macular edema resolution so that the laser grid can be performed sooner. Our results show that a single injection is sufficient to facilitate that process.

In our result, the mean difference of visual acuity in the combination therapy group was 0.35 or greater than 15 characters in 1 month. The result was similar at the 3-month follow-up (Table 2). In laser therapy group, the mean difference of visual acuity was less than 15 characters at the 1-month follow-up and showed similar results at the 3-month 


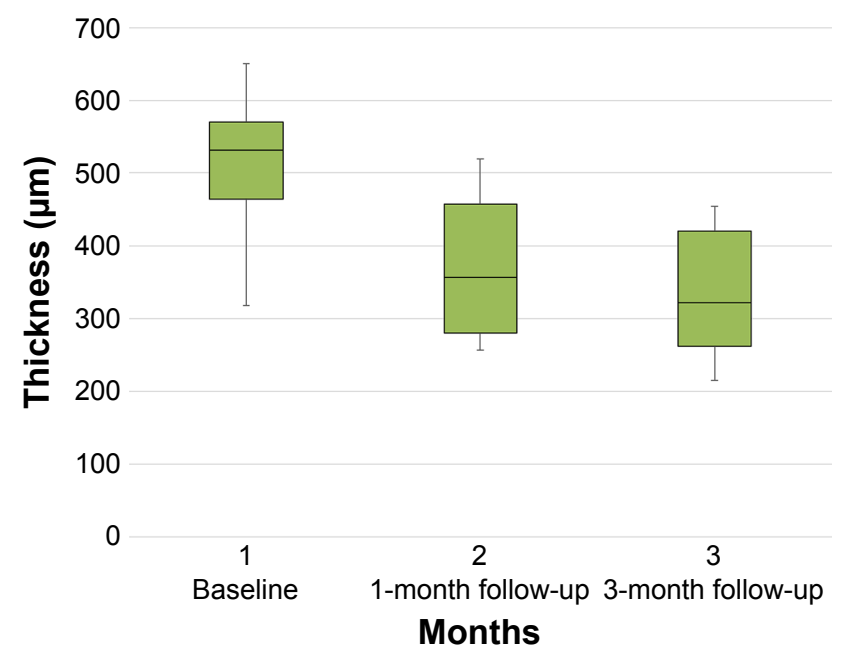

Figure I Central retinal thickness on laser and bevacizumab.

follow-up (Table 4). The mean decrease in macular thickness in the combination therapy group and laser-only group showed no statistical difference at 1 month and 3 months (Figures 1 and 2). This could mean that the laser effect on both groups produced the same effect. The increase of visual acuity was significantly different statistically between the two groups at 1 month and 3 months. We believe, on the combination group, the anti-VEGF had an effect on rapid resolution of the edema, due to which we could perform laser treatment immediately to reduce the oxygen consumption in the macula and decrease the VEGF. We believe this was also one of the factors that resulted in a significant increase in visual acuity in the combination group.

\section{Limitations}

The main limitation of this study was the follow-up duration. The follow-up was limited to only 7 months after the

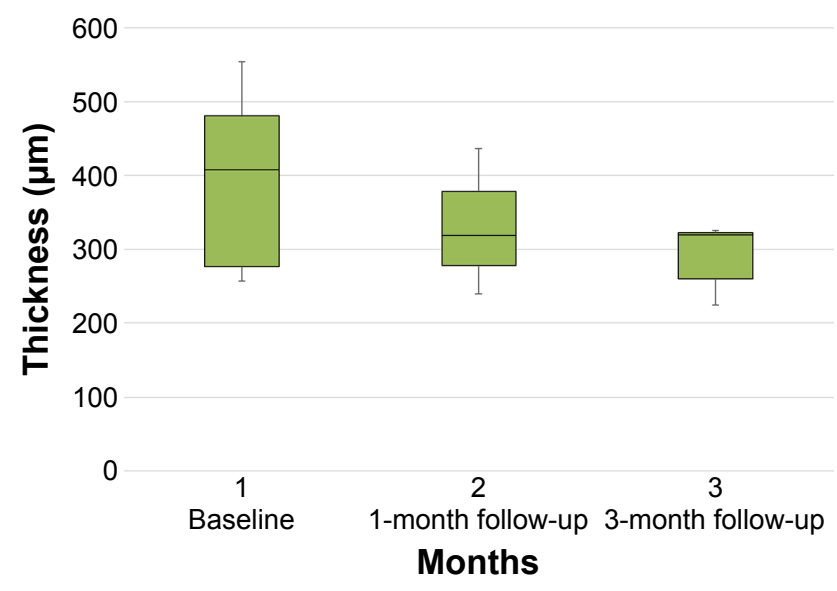

Figure 2 Central retinal thickness on laser grid group. first recruitment. Therefore, the effectiveness of a single injection in the long run has to be determined to rule out the rebound condition that might occur on BRVO. We could not get the data of the first 1-week period after diagnosis and the ischemic status of the BRVO. This was also considered a limitation of the study that may confoundthe results.

\section{Conclusion}

In conclusion, visual acuity improvement was better in laser photocoagulation therapy in combination with bevacizumab compared to that with laser photocoagulation therapy alone in macular edema secondary to BRVO. There was no difference in decrease of macular thickness between the two groups, hence a future study is needed with bigger sample size and longer follow-up period.

Combination therapy of single bevacizumab and laser photocoagulation can be considered an alternative therapy for macular edema secondary to BRVO.

\section{Disclosure}

The authors report no conflicts of interest in this work.

\section{References}

1. Rehak J, Rehak M. Branch retinal vein occlusion: pathogenesis, visual prognosis, and treatment modalities. Curr Eye Res. 2008;33(2): 111-131.

2. Hayreh SS, Zimmerman MB. Branch retinal vein occlusion: natural history of visual outcome. JAMA Ophthalmol. 2014;132(1):13-22.

3. Rogers SL, McIntosh RL, Lim L, et al. Natural history of branch retinal vein occlusion: an evidence-based systematic review. Ophthalmology. 2010;117(6):1094-1101.

4. Cugati S, Wang JJ, Rochtchina E, Mitchell P. Ten-year incidence of retinal vein occlusion in an older population: the Blue Mountains Eye Study. Arch Ophthalmol. 2006;124(5):726-732.

5. Ehlers JP, Fekrat S. Retinal vein occlusion: beyond the acute event. Surv Ophthalmol. 2011;56(4):281-299.

6. Campochiaro PA, Heier JS, Feiner L, etal. Ranibizumab for macular edema following branch retinal vein occlusion: six-month primary end point results of a Phase III study. Ophthalmology. 2010;117(6):1102-1112.

7. Noma H, Funatsu H, Yamasaki M, et al. Pathogenesis of macular edema with branch retinal vein occlusion and intraocular levels of vascular endothelial growth factor and interleukin-6. Am J Ophthalmol. 2005;140(2):256-261.

8. Campochiaro PA, Bhisitkul RB, Shapiro H, Rubio RG. Vascular endothelial growth factor promotes progressive retinal nonperfusion in patients with retinal vein occlusion. Ophthalmology. 2013;120(4): 795-802.

9. Mehany SA, Mourad KM, Shawkat AM, Sayed MF. Early Avastin management in acute retinal vein occlusion. Saudi J Ophthalmol. 2010; 24(3):87-94.

10. Loukianou E, Brouzas D, Chatzistefanou K, Koutsandrea C. Clinical, anatomical, and electrophysiological assessments of the central retina following intravitreal bevacizumab for macular edema secondary to retinal vein occlusion. Int Ophthalmol. 2016;36(1):21-36.

11. Campochiaro PA, Brown DM, Awh CC, et al. Sustained benefits from ranibizumab for macular edema following central retinal vein occlusion: twelve-month outcomes of a Phase III study. Ophthalmology. 2011; 118(10):2041-2049 
12. Falavarjani KG, Nguyen QD. Adverse events and complications associated with intravitreal injection of anti-VEGF agents: a review of literature. Eye (Lond). 2013;27(7):787-794.

13. Azad R, Chandra P, Gupta R. The economic implications of the use of anti-vascular endothelial growth factor drugs in age-related macular degeneration. Indian J Ophthalmol. 2007;55(6):441-443.

14. Heier JS, Campochiaro PA, Yau L, et al. Ranibizumab for macular edema due to retinal vein occlusions: long-term follow-up in the HORIZON trial. 2012;119(4);802-809.

15. Miller JW, Le Couter J, Strauss EC, Ferrara N. Vascular endothelial growth factor a in intraocular vascular disease. Ophthalmology. 2013; 120(1):106-114

16. Narayanan R, Panchal B, Stewart MW, et al. Grid laser with modified pro re nata injection of bevacizumab and ranibizumab in macular edema due to branch retinal vein occlusion: MARVEL report no 2. Clin Ophtahlmol. 2016;10:1023-1029.

17. Solaiman KA, Diab MM, Abo-Elenin M. Intravitreal bevacizumab and/or macular photocoagulation as a primary treatment for diffuse diabetic macular edema. Retina. 2010;30(10):1638-1645.

18. Michaelides M, Kaines A, Hamilton RD, et al. A prospective randomized trial of intravitreal bevacizumab or laser therapy in the management of diabetic macular edema (BOLT study) 12-month data: report 2. Ophthalmology. 2010;117(6):1078-1086.

19. Solomon SD, Lindsley KB, Krzystolik MG, Vedula SS, Hawkins BS. Intravitreal bevacizumab versus ranibizumab for treatment of neovascular age-related macular degeneration: findings from a cochrane systematic review. Ophthalmology. 2016;123(1):70-77.

20. Kodjikian L, Souied EH, Mimoun G, et al. Ranibizumab versus bevacizumab for neovascular age-related macular degeneration: results from the GEFAL noninferiority randomized trial. Ophthalmology. 2013;120(11):2300-2309.

21. Landa G, Amde W, Doshi V, et al. Comparative study of intravitreal bevacizumab (Avastin) versus ranibizumab (Lucentis) in the treatment of neovascular age-related macular degeneration. Ophthalmologica. 2009;223(6):370-375.
22. Dakin HA, Wordsworth S, Rogers CA, et al. Cost-effectiveness of ranibizumab and bevacizumab for age-related macular degeneration: 2-year findings from the IVAN randomised trial. BMJ Open. 2014;4(7):e005094.

23. Risard SM, Pieramici DJ, Rabena MD, et al. Intravitreal ranibizumab for macular edema secondary to central retinal vein occlusion. Retina. 2011;31(6):1060-1067.

24. Campochiaro PA, Hafiz G, Channa R, et al. Antagonism of vascular endothelial growth factor for macular edema caused by retinal vein occlusions: two-year outcomes. Ophthalmology. 2010;117(12):2387-2394.

25. Spaide RF, Chang LK, Klancnik JM, et al. Prospective study of intravitreal ranibizumab as a treatment for decreased visual acuity secondary to central retinal vein occlusion. Am J Ophthalmol. 2009;147(2): 298-306.

26. Campochiaro PA, Hafiz G, Shah SM, et al. Ranibizumab for macular edema due to retinal vein occlusions: implication of VEGF as a critical stimulator. Mol Ther. 2008;16(4):791-799.

27. Pieramici DJ, Rabena M, Castellarin AA, et al. Ranibizumab for the treatment of macular edema associated with perfused central retinal vein occlusions. Ophthalmology. 2008;115(10):e47-e54.

28. Diabetic Retinopathy Clinical Research Network; Scott IU, Edwards AR, et al. A Phase II randomized clinical trial of intravitreal bevacizumab for diabetic macular edema. Ophthalmology. 2007;114(10):1860-1867.

29. Ohashi H, Oh H, Nishiwaki H, Nonaka A, Takagi H. Delayed absorption of macular edema accompanying serous retinal detachment after grid laser treatment in patients with branch retinal vein occlusion. Ophthalmology. 2004;111(11):2050-2056.

30. Alfaro DV III, Jablon EP, Kerrison JB, et al. Ranibizumab for the treatment of branch retinal vein occlusion-associated cystoid macular edema [abstract]. Invest Ophthalmol Vis Sci. 2008;49:2699.

31. Wykrota H, Trzciakowski K, Gierek-Lapinska A. Ranibizumab treatment of macular edema secondary to retinal vein occlusion [abstract]. 8th EURETINA Congress, May 22-25, 2008.
Clinical Ophthalmology

\section{Publish your work in this journal}

Clinical Ophthalmology is an international, peer-reviewed journal covering all subspecialties within ophthalmology. Key topics include: Optometry; Visual science; Pharmacology and drug therapy in eye diseases; Basic Sciences; Primary and Secondary eye care; Patient Safety and Quality of Care Improvements. This journal is indexed on Submit your manuscript here: http://www.dovepress.com/clinical-ophthalmology-journal

\section{Dovepress}

PubMed Central and CAS, and is the official journal of The Society of Clinical Ophthalmology (SCO). The manuscript management system is completely online and includes a very quick and fair peer-review system, which is all easy to use. Visit http://www.dovepress.com/ testimonials.php to read real quotes from published authors. 